Karolina Krakowiak', Marta Dąbrowska², Filip Buła', Anna kobacz², Dorota Rojek', Elżbieta M. Grabczak' ${ }^{2}$, Antoni Krzeski ${ }^{3}$, Rafał Krenke ${ }^{2}$

'Students' Research Group "Alveolus", Medical University of Warsaw, Poland

'Department of Internal Medicine, Pulmonary Diseases and Allergy, Medical University of Warsaw, Poland

${ }^{3}$ Department of Otorhinolaryngology, Medical University of Warsaw, Poland

\title{
Speech therapy — a non-pharmacological method to manage difficult-to-treat chronic cough
}

The authors declare no financial disclosure

\begin{abstract}
Cough is the most common symptom of respiratory diseases. The results of management of chronic cough in adults are still unsatisfactory. Unexplained and difficult-to-treat chronic cough causes significant impairment in patients' quality of life. The results of recent studies suggest that speech therapy (speech language intervention) is one of the few methods which are usefull in management of persistent chronic cough. We present a case of a patient with chronic cough due to chronic nonallergic rhinitis and gastroesophageal reflux disease, who had been unsuccessfully treated for 18 years. In the patient speech therapy resulted in a significant decrease of cough severity and improvement of quality of life.
\end{abstract}

Key words: chronic cough, cough management, speech therapy

Adv. Respir. Med. 2017; 85: 116-120

\section{Introduction}

Cough is one of the most common symptoms of respiratory diseases. Chronic cough (CC) (lasting $>8$ weeks) affects about $10-20 \%$ of adults [1]. Due to a large number of CC causes, the causal diagnosis is often challenging. Thorough analysis of medical history that includes symptoms, comorbidities and medications should be a starting point for differential diagnosis of CC causes. Chest radiograph (CXR) is a pivotal diagnostic procedure in the further diagnostic work-up. This may reveal not only pulmonary but also extrapulmonary abnormalities that are associated with CC. On the other hand, in a significant proportion of patients with CC, CXR does not show any abnormal findings. The most common causes of CC in non-smoking adults with normal CXR result, are as follows: upper airway cough syndrome (UACS), gastroesophageal reflux disease (GERD), asthma, nonasthmatic eosinophilic bronchitis and treatment with angiotensin convertase enzyme inhibitors (ACEI) [1, 2].

The results of management of CC in adults are highly unsatisfactory $[1,3,4]$. It may be a result of either ineffective management of properly diagnosed underlying diseases (difficult-to-treat CC) or failure to diagnose the cause of CC. According to ACCP recommendations, unexplained chronic cough (UCC) is diagnosed in as many as $5-10 \%$ of all adults with CC [4]. Persistent CC significantly impairs the quality of life [5].

There are only few methods of management of patients with UCC [4]. These include pharmacological treatment with gabapentin and speech and language intervention (the other names: speech or voice therapy). The latter is the most documented method of management of UCC or difficult-to-treat cough [4]. Speech therapy consists of education, learning strategies to reduce cough, respiratory and speech exercises [6-8]. We present a case of a patient with persistent, difficult-

Address for correspondence: Marta Dąbrowska, Students' Research Group “Alveolus”, Medical University of Warsaw, Poland, e-mail: mdabrowska@mp.pl 
-to-treat chronic cough due to gastroesophageal reflux disease, who was finally succesfully treated with speech therapy.

\section{Case report}

44-year-old, non-smoking female, a nurse, was referred to the Department of Internal Medicine, Pulmonary Diseases and Allergy to diagnose the cause of CC, which had persisted for approximately ten years. Previously, the patient had been unsuccessfully treated with many different pharmacotherapies, including antileukotrienes, inhaled corticosteroids, bronchodilators and antibiotics.

The patient was admitted to our department first in 2008 because of persistent CC. The beginning of cough had been associated with an acute respiratory infection. The cough was dry, occured mainly in the morning and in the evening. It was accompanied by runny nose and nasal congestion. The patient denied chest pain, shortness of breath, haemoptysis or general symptoms like fever or weight loss. The physical examination revealed no significant abnormalities. CXR showed small, fibrotic plate atelectasis in the middle field of the right lung, but computed tomography (CT) of the chest revealed that the lung parenchyma and mediastinal organs were normal. The result of spirometry was within the norm and methacholine inhalation challenge was negative $\left(\mathrm{PC}_{20}\right.$ $>16 \mathrm{mg} / \mathrm{ml}$ ), which allowed to exclude asthma and other obstructive airway diseases. There were no eosinophils in induced sputum, which contradicted the diagnosis of nonasthmatic eosinophilic bronchitis. Skin prick tests with common aeroallergens were negative. CT scan of the paranasal sinuses showed small beads of the mucous membrane in the maxillary sinus, deviated nasal septum and enlarged right middle turbinate. The patient was consulted by the laryngologist, who diagnosed chronic nonallergic rhinosinusitis and recommended intranasal glicocorticosteroids. Videolaryngoscopy revealed redness of the posterior part of the larynx suggesting possibility of laryngo-pharyngeal reflux. The function of the larynx was normal. In order to exclude gastroesophageal reflux disease as a potential cause of cough, 24hour esophageal $\mathrm{pH}$ monitoring was performed, which revealed acid reflux episodes (DeMesster score 21.5, normal range < 14.7), but no relationship between cough and reflux episodes was documented. The treatment with intranasal budesonide, anti-reflux diet and pantoprazol 40 mg bid was introduced for 8 weeks, but it failed to reduce cough intensity. Therefore, esophageal 24-hour multichannel intraluminal impedance$\mathrm{pH}$ monitoring was performed that confirmed the presence of weakly acid reflux reaching the proximal esophagus and larynx. Neither diet, life style modification nor medications (pantoprazol, esomeprazol, ranitidine, cisaprid) resulted in reduction of cough intensity. Difficult-to-treat cough due to UACS (chronic nonallergic rhinosinusities) and GERD (weakly acid) was diagnosed. The patient had been treated because of cough in our outpatient clinic from 2008 till 2015.

In 2015, a trial of treatment with gabapentin (300 mg bid) was introduced, but was ineffective and had to be ceased due to adverse effects (dizziness and nausea). As all treatment attempts were unsuccessful and CC significantly affected patients' quality of life, the patient was referred to speech therapy. Before initiation of speech therapy, cough severity and its influence on quality of life was assessed in accordance with ERS guidelines [9]. We applied Visual Analogue Scale (VAS) for subjective assessment of cough severity and Leicester Cough Questionnaire (LCQ) for evaluation of influence of cough on patients quality of life $[9,10]$. Moreover, cough challenge test with capsaicin was performed to assess the sensitivity to inhaled irritants $[9,10]$.

Speech therapy was conducted by a speech therapist using a method developed by our team based on the technique described by Vertigan et al. [6]. It included education of vocal hygiene, teaching strategies to relax diaphragm and reduce cough and laryngeal irritation. Breathing and vocal exercises along with education were used. The entire therapy consisted of eight 45 -minute sessions once a week, 2 of which were individual and 6 were continued in a group.

After the speech therapy, the patient declared significant, subjective improvement, that was confirmed by reduction of cough severity measured by VAS and improvement in quality of life documented in LCQ. There was no change in the threshold of cough provocation in the capsaicin test. The detailed results of VAS, LCQ and capsaicin provocation test before and after therapy are shown in Table 1. In the patient opinion, the breathing exercises were the most effective component of the speech therapy.

\section{Discussion}

Although various therapeutic approaches to patients with CC have been evaluated, there is no convincing data on the effectiveness of these 


\section{Table 1. Results of the speech therapy}

\begin{tabular}{lcc}
\hline & Before speech tehrapy & After speech therapy \\
\hline Severity of cough measured by VAS $(\mathrm{mm})$ & 75 & 28 \\
Quality of life measured by total LCO & 11.6 & 16.1 \\
physical domain of LCO & 3.25 & 4.5 \\
psychological domain of LCO & 3.57 & 6.14 \\
social domain od LCO & 4.75 & 5.5 \\
Sensitivity of cough reflex measured & $\mathrm{C} 2-7.84$ & $\mathrm{C}-7.84$ \\
by capsaicin challenge $(\mu \mathrm{M})$ & & \\
VAS - visual analogue scale, range 0-100 mm; LCO - Leicester Cough Questionnaier (LCO), range 3-21 points; the higher the value, the better quality of life in \\
patients with cough; C2 - concentration of capsaicin, which induce 2 coughs during provocation challenge test with capsaicin
\end{tabular}

therapies, and the management of chronic cough is still challenging [4]. Our patient had been unsuccesfully treated for 18 years (1998-2016) before her cough was significantly reduced due to the speech therapy. Although in most patients CC is a symptom of non-life-threatening disease, it significantly lowers quality of life, in both physical and psychosocial domain $[1,5]$. In many aspects the decrease of life quality in patients with CC is comparable to that experienced by patients with the chronic obstructive lung disease [1]. Therefore, the effective therapies for CC are one of the most important unmet needs in respiratory diseases.

The effectiveness of CC management, however, is highly unsatisfactory $[3,11,12]$. In the study by Haque et al. [3] $42 \%$ of patients with CC did not improve despite causal treatment. Our previous study showed that only $55 \%$ of patients with CC reported significant decrease in cough severity as a result of applied therapy [11]. Similarly, in the recently published survey study approximately $36 \%$ of patients with CC declared no effect of cough therapy [12]. According to the ACCP guidelines, persistent untreatable cough refers to $5-10 \%$ of all CC patients undergoing treatment and up to $46 \%$ of patients managed in specialised cough clinics [4]. Among them, there are patients with recognised cough reasons, but refractory to cough therapy and patients with unexplained cough causes [4].

Since UACS and GERD had been diagnosed as the causes of CC in our patient, the causative treatment directed to these two conditions seemed to be the most reasonable therapeutic option. However, the effectiveness of treatment of CC due to GERD is doubtful. One meta-analysis of treatment efficacy with proton pump inhibitors (PPI) failed to confirm their effectiveness [13]. Similarly, the treatment of cough due to UACS, especially nonallergic rhinosinusitis, is thought to be wearisome and only partially successful [14].
The above comments may explain the failure of pharmacotherapy in our patient.

The unsatisfactory effectiveness of CC management contributed to the popularity of the theory of cough hypersensitivity syndrome [15]. Its pathophysiology is still not absolutely clear, it probably results from central and peripheral sensitisation, usually after a viral infection. Thus, regardless of CC reason, the failure of cough treatment may result from hypersensitivity of cough reflex [16].

In fact, there are only two methods available for management of patients with refractory CC: centrally acting neuromodulators (gabapentin and pregbalin) or speech and language therapy [4]. As the usage of gabapentin is limited due to its side effects, the speech therapy is the most promising method of management of UCC. This technique is adapted from the treatment of hyperfunctional voice disorders. The first studies concerning speech therapy techniques in treatment of CC came from the 80 s of 20 th century, while the first randomised trial was published in 2006 [6]. Speech therapy for CC is multifactorial intervention, which may include different elements: education about cough, identification of cough triggers, instruction on cough suppression techniques, breathing exercises, vocal hygiene and hydration techniques and sometimes some forms of counselling. These treatment techniques generally are delivered by speech and language therapists or physiotherapists and usually consist of 2-4 sessions [7, 8, 17]. The mechanism of reducing cough by speech pathology intervention is yet to be determined. Perhaps, breathing exercises allow to relax the throat, neck, and shoulder muscles, which may help to reduce the adductor activity of the vocal folds during expiration in patients with CC and paradoxical vocal fold movement [7]. To our knowledge, the speech therapy has not been available for patients with CC in Poland. Hence, 
we undertook the task of working out the voice therapy for patients with CC treated in our institution. The speech therapy was implemented and performed by the phoniatrist (DR) and speech and language therapists (AŁ). It consisted of education about cough and vocal hygiene, identification of cough triggers, instruction on cough suppression techniques, conscious breathing, relaxing and speech exercises. They included breathing control, diaphragmatic breathing and relaxed breathing control techniques. Continuation of the therapy in a group was a new approach, worked out by our team as a component of psychological support for the patients.

An important problem in all studies on management of CC is how to define the response to cough therapy. Numerous studies were performed to define clinical tools for measurement of cough. Among them, there are cough monitors, cough specific quality of life questionnaires, VAS and sensitivity to inhaled cough irritants measured in cough challenge test $[9,10]$. To follow the effect of speech therapy in our patient, we used the above mentioned tools with the exception of cough monitor. Both VAS as a subjective scale of cough severity, and Polish version of LCQ [18] showed significant improvement. These findings are similar to results published by other authors [6, 19]. Interestingly, there was no change in cough responsiveness assessed by capsaicin challenge, and this is also consistent with results of other authors [19].

Although speech therapy is a useful method of CC treatment, the persistent CC still remains a major problem. Therefore, the studies concerning new antitussive drugs are necessary. Recently the phase 2 clinical study has been published by Abdulqawi et al. [20], who presented P2X3 receptor antagonist (AF-219) as an effective drug in refractory chronic cough. Further studies are in progress.

In conclusion, the speech therapy was the most effective method of treatment of persistent CC in our patient. As CC is a common complaint and the effectiveness of pharmacological therapies are rather limited, the speech therapy may become useful therapeutic approach for numerous patients with persistent CC.

\section{Conflict of interest}

The authors declare no conflict of interest.

\section{References:}

1. Morice AH, McGarvey L, Pavord I, et al. British Thoracic Society Cough Guideline Group. Recommendations for the manage- ment of cough in adults. Thorax. 2006; 61 Suppl 1: i1-24, doi: 10.1136/thx.2006.065144, indexed in Pubmed: 16936230.

2. Irwin RS, Baumann MH, Bolser DC, et al. American College of Chest Physicians (ACCP). Diagnosis and management of cough executive summary: ACCP evidence-based clinical practice guidelines. Chest. 2006; 129(1 Suppl): 1S-23S, doi: 10.1378/chest.129.1 suppl.1S, indexed in Pubmed: 16428686.

3. Haque RA, Usmani OS, Barnes PJ. Chronic idiopathic cough: a discrete clinical entity? Chest. 2005; 127(5): 17101713, doi: 10.1378/chest.127.5.1710, indexed in Pubmed: 15888850.

4. Gibson P, Wang G, McGarvey L, et al. CHEST Expert Cough Panel. Treatment of Unexplained Chronic Cough: CHEST Guideline and Expert Panel Report. Chest. 2016; 149(1): 27-44, doi: 10.1378/chest.15-1496, indexed in Pubmed: 26426314.

5. Polley L, Yaman N, Heaney L, et al. Impact of cough across different chronic respiratory diseases: comparison of two cough-specific health-related quality of life questionnaires. Chest. 2008; 134(2): 295-302, doi: 10.1378/chest.07-0141, indexed in Pubmed: 18071022.

6. Vertigan AE, Theodoros DG, Gibson PG, et al. Efficacy of speech pathology management for chronic cough: a randomised placebo controlled trial of treatment efficacy. Thorax. 2006; 61(12): 1065-1069, doi: 10.1136/thx.2006.064337, indexed in Pubmed: 16844725.

7. Chamberlain S, Birring SS, Garrod R. Nonpharmacological interventions for refractory chronic cough patients: systematic review. Lung. 2014; 192(1): 75-85, doi: 10.1007/ s00408-013-9508-y, indexed in Pubmed: 24121952.

8. Gibson PG, Vertigan AE. Speech pathology for chronic cough: a new approach. Pulm Pharmacol Ther. 2009; 22(2): 159-162, doi: 10.1016/i.pupt.2008.11.005, indexed in Pubmed: 19061964.

9. Morice AH, Fontana GA, Belvisi MG, et al. European Respiratory Society (ERS). ERS guidelines on the assessment of cough. Eur Respir J. 2007; 29(6): 1256-1276, doi: 10.1183/09031936.00101006, indexed in Pubmed: 17540788.

10. Boulet LP, Coeytaux RR, McCrory DC, et al. CHEST Expert Cough Panel. Tools for assessing outcomes in studies of chronic cough: CHEST guideline and expert panel report. Chest. 2015; 147(3): 804-814, doi: 10.1378/chest.14-2506, indexed in Pubmed: 25522203.

11. Grabczak EM, Dąbrowska M, Paplińska-Goryca M, et al. Ocena wrażliwości odruchu kaszlowego na podstawie próby prowokacji z kapsaicyną -wyniki wstępne. Pol Mer Lek. 2014; 36: 180-185.

12. Dąbrowska M, Grabczak EM, Arcimowicz M, et al. Chronic cough - assessment of treatment efficacy based on two questionnaires. Arch Med Sci. 2014; 10(5): 962-969, doi: 10.5114/aoms.2014.40642, indexed in Pubmed: 25395948.

13. Chamberlain SAF, Garrod R, Douiri A, et al. The impact of chronic cough: a cross-sectional European survey. Lung. 2015; 193(3): 401-408, doi: 10.1007/s00408-015-9701-2, indexed in Pubmed: 25787221.

14. Chang AB, Lasserson TJ, Kiljander TO, et al. Systematic review and meta-analysis of randomised controlled trials of gastro-oesophageal reflux interventions for chronic cough associated with gastro-oesophageal reflux. BMJ. 2006; 332(7532): 11-17, doi: 10.1136/bmj.38677.559005.55, indexed in Pubmed: 16330475.

15. Pratter MR. Chronic upper airway cough syndrome secondary to rhinosinus diseases (previously referred to as postnasal drip syndrome): ACCP evidence-based clinical practice guidelines. Chest. 2006; 129(1 Suppl): 63S-71S, doi: 10.1378/chest.129.1_suppl.63S, indexed in Pubmed: 16428694 .

16. Morice AH, Millqvist E, Belvisi MG, et al. Expert opinion on the cough hypersensitivity syndrome in respiratory medicine. Eur Respir J. 2014; 44(5): 1132-1148, doi: 10.1183/09031936.00218613, indexed in Pubmed: 25142479. 
17. Birring SS, Kavanagh J, Lai K, et al. Adult and paediatric cough guidelines: Ready for an overhaul? Pulm Pharmacol Ther. 2015; 35: 137-144, doi: 10.1016/j.pupt.2015.01.007, indexed in Pubmed: 25681276.

18. Vertigan AE, Theodoros DG, Winkworth AL, et al. Chronic cough: a tutorial for speech-language pathologists. J Med Speech Lang Pathol. 2007; 15: 189-206.

19. Dąbrowska M, Krakowiak K, Radlińska O, et al. Validation of the Polish Version of the Chronic Cough Quality of
Life Questionnaire (Leicester Cough Questionnaire). Adv Clin Exp Med. 2016; 25(4): 649-653, indexed in Pubmed: 27629838.

20. Chamberlain Mitchell SAF, Garrod R, Clark L, et al. Physiotherapy, and speech and language therapy intervention for patients with refractory chronic cough: a multicentre randomised control trial. Thorax. 2017; 72(2): 129-136, doi: 10.1136/thoraxinl-2016-208843, indexed in Pubmed: 27682331. 